\title{
SER-SE RIO, VENTO, MULHER, E $O$ QUE QUISER: A INDIVIDUAÇÃO E A FORMAÇÃO DE PROFESSORES
}

\author{
Alice Copetti Dalmaso* \\ Deisi Sangoi Freitas ${ }^{* *}$ \\ Magda SCHMIDT $^{* * *}$
}

\begin{abstract}
RESUMO: O presente artigo propóe pensar sobre o processo de individuação na formação de professores, aprofundando o olhar nos processos que permeiam a formação docente, muitas vezes legitimada por modos de ser que delimitam uma "forma". Utilizamos, principalmente, o diálogo teórico entre o escritor Mia Couto e o filósofo Gilbert Simondon, para trazer à tona a operação de individuaçáo que lida com outros tempos e espaços formativos. A individuaçáo que conversa com a literatura nos permite perceber a processualidade do vivo, em seu caráter de inacabamento, e das nossas individuaçôes infinitas, efetuadas pelo afetivo. Mia Couto, através da sua escrita literária, ilustra a não-identidade de Simondon e de como acessamos o mundo (e somos acessados por ele) quando nos desvencilhamos de modos de ser definidos e determinados. Assim, desconstruimos o indivíduo tomado como entidade acabada e fazemos aparecer o sujeito em co-existência com o mundo.
\end{abstract}

Palavras-chave: : Individuação; Formação de professores; Tempo; Espaço.

\section{BEING A RIVER, WIND, WOMAN, AND WHATEVER YOU WANT: INDIVIDUATION AND TEACHER EDUCATION}

ABSTRACT: This article proposes to reflect upon the process of individuation in teacher education, broadening the view on processes which permeate teacher training, often legitimized by ways of being that delimit a "form". This reflection is mainly based on the theoretical dialogue between the writer Mia Couto and the philosopher Gilbert Simondon, aiming to highlight the operation of individuation that deals with other times and formative spaces. Observing individuation through dialoguing with literature allows us to realize the processuality of the living subject, in their character of incompleteness, and of our endless

\footnotetext{
* Universidade Federal de Santa Maria, Santa Maria, RS., Brasil. E-mail para contato: alicedalmaso@gmail.com.

** Universidade Federal de Santa Maria, Santa Maria, RS., Brasil. E-mail para contato: deisisf@ gmail.com.

*** Instituto Aprender, Santa Maria, RS., Brasil. E-mail para contato: magda_sch@yahoo.com.br.
} 
individuations, performed by the affective domain. Mia Couto, through his literary writings, illustrates the non-identity of Simondon and how we access the world (and are accessed by it) when we get rid of defined and determined ways of being. Thus, we deconstruct the individual that is taken as a finished entity and provoke the emergence of the subject in co-existence with the world.

Keywords: Individuation; Teacher education; Time; Space.

\section{ÊTRE FLEUVE, VENT, FEMME ET CE QU'ON VEUT: L'INDIVIDUATION ET LA FORMATION D'ENSEIGNANTS}

RÉSUMÉ: Cet article propose à réfléchir sur le processus d'individuation dans la formation d'enseignants, en approfondissant le regard sur les processus qui traverse cette formation, souvent légitimée par des manières d'être qui délimitent une «forme». On a utilisé principalement le dialogue théorique entre l'écrivain Mia Couto et le philosophe Gilbert Simondon pour mettre en évidence l'opération d'individuation qui travaille avec d'autres temps et espaces formatifs. L'individuation qui dialogue avec la littérature permet de comprendre la processualité du "vivant», dans son caractère d'inachèvement et de nos individuations infinies, réalisées par l'affectif. Mia Couto, par son écriture littéraire, illustre la non-identité de Simondon et de comment on accède au monde (et comment on est accédé par lui) quand on se débarrasse de manières d'être définies et déterminées. Ainsi, on déconstruit l'individu pris comme entité finie et on fait apparaître le sujet celui qui coexiste avec le monde.

Mots-clés: Individuation; Formation d'enseignants; Temps; Espace.

Nenhum rio é apenas um curso de água, esgotável sob o prisma da hidrologia. Um rio é uma entidade vasta e múltipla. Compreende as margens, as áreas de inundação, as zonas de captação, a flora, a fauna, as relaçôes ecológicas, os espíritos, as lendas, as histórias. [...] Habituados a olhar as coisas como engenhos, esquecemos que estamos perante um organismo que nasce, respira e vive de trocas com a vizinhança. (COUTO, 2011, p. 52-53)

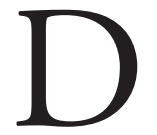

isso também somos feitos: uma rede de relações múltiplas que nos constituem e que nos definem, provisoriamente. Assim é a vida, o ambiente e as costuras que fazemos. O escritor e biólogo Mia Couto nos lança para mundos ainda não pensados, codificados e escritos, quando nos tira da centralidade do mundo. Mia, de início, nos ajuda a pensar o indivíduo como algo múltiplo, deformável, e acima de tudo, não-individualizado. A literatura do 
escritor não é o foco desse artigo, mas traremos algumas passagens para compor a dimensão de uma escrita que nos leva a conhecer um outro mundo: o do não ser.

Buscamos, para tanto, construir juntamente com o filósofo da individuação, Gilbert Simondon, a desconstituição da forma homem como entidade acabada, definível e resoluta. Porque, para nós, pensar sobre formação humana implica percebermo-nos como indivíduos que parecem formados demasiadamente, cheios de certezas, carregados de verdades. Desinvestir no indivíduo/professor é mostrar a sensibilidade impessoal, coletiva e singular que portamos. Realizar esse pensamento implica a possibilidade de engendrarmos uma política que dissemina "[...] combinatórias, silêncios, transmutaçôes de coisas, eu e impessoais parasitados [...]”. (HENZ, 2010, p. 5) É retirar das formas construídas algo intrínseco do indivíduo (essência) e próprio de uma identidade já que, para Simondon, o ser individuado é incompatível consigo mesmo.

O objetivo dessa escrita, portanto, não é propor novas formas de ser professor. Nossa intenção é justamente despir certa vaidade professoral que sustenta a política de informar para uma "forma", lidando com uma performance dotada de certezas, representaçốes e eficiências. É movimentar-se, colocar-se em suspensão, problematizar-se. Resistir e fazer enfrentamento aos modos que mantém a constituição de espaços e tempos de formação humana. Tempos escolarizados direcionam nossa atenção para os resultados e não para seu processo, a condição de trabalho sobre si mesmo, do cultivo de um aprender no encontro com conceitos, pessoas, corpos em processo; um tempo utilitário, em que professores vestem sua função de educar 300 alunos, num "período" de vida de 40 horas semanais; tempo que desconsidera o presente e nossa imersão nas experiências que nos acontecem agora, confiando nos processos naturais que nos constituem. O tempo e o que forma o espaço, ao nosso entorno, desse modo, tornam-se sempre representativos e impossibilitados de serem reinventados.

Estes escritos caminham com a literatura no objetivo de intensificar o excesso do qual somos constituídos e que nos permite ir mais além de nossa forma humanizada. O desejo é de se fazer sentir outro, num mundo do trabalho em que produzir equivale a pouco tempo livre, exigências de formas, modos eficientes, discursos subjetivantes, incompatíveis por si só, como se pretende mostrar, com a nossa natureza individuante e sempre imprevisível.

\section{Individuação como processo não causal}

Deixar de pensar-se como eu para viver-se como fluxo, um conjunto de fluxos, em relação com outros fluxos fora de si e dentro de si próprio. Deixar de operar pelo "eu" e, nesse caso, como um ideal construído, é encontrar, instaurar 
um máximo de conexóes. Circular pelo que ativa, vibra, toca; fazer aparecer o devir em suas lentidôes, correntes, sopros, transmutações e deformaçóes.

Quando se trata, entretanto, de explicar a individualidade, de maneira geral, procuramos achar o elemento primordial que dá origem a um ente pronto, realizado, acabado (em torno de si). O interesse de Gilbert Simondon, ao qual recorremos a maior parte desses escritos, é justamente abandonar essa polaridade do indivíduo: o ponto de partida e o ponto de chegada. A intenção é pensar na operação (e não no princípio) da individuação, no individuar-se, nesse intervalo ignorado em que reside a própria vida. Pensar o indivíduo se realizando em sua processualidade, sem procurar no passado um princípio que o justifique no hoje, posto que é no presente que o indivíduo se individua. Interessa, assim como a Simondon, conhecer o indivíduo pela individuação, e não a individuação pelo indivíduo. (DA COSTA, 2002)

Não pensar o indivíduo como uma substância ou matéria que já porta todo seu sentido, reduzido a algo pronto e pré-determinado, soa quase como afronta, principalmente nos interstícios educacionais. Há uma exigência maior da sensibilidade em conseguir se apreender como ato, e não como algo que é uma unidade, pré-definida e fechada em si mesmo. Somos agentes do ato de individuação, através do qual nos manifestamos e existimos. (SIMONDON, 2009) Carregamos, armazenamos, transformamos e reatualizamos um esquema que nos constitui, e propagamo-lo ao individuarmo-nos, ao vivermos. É nesse sentido que nunca estamos acabados, finalizados, porque permanecemos nos individuando através do tempo.

Atentamos a isso, a esse ente que se apresenta em seu imediatismo - e não à sua constituição material ou formal -, em sua própria operação de individuação, para incitar o movimento de deixar de pensar o indivíduo pronto. Para tanto, é preciso perceber o individuo tomado como próprio "[...] meio de individuação, um meio que implica uma realidade pré-individual, um campo de singularidades pré-individuais [...]”. (ORLANDI, 1993, p. 90) Ou seja, nossa natureza carrega uma "carga" em constante movimento de diferenciação, como uma condição, prévia (pré), de todo processo individuante. Não somos somente resultado, mas mesmo meio de individuação: "[...] nos alimentamos desse meio, carregamos ele conosco, nosso suporte de realidade ainda não individualizado [...]”. (DELEUZE, 1993, p. 120) Esse meio é intrínseco a nós e fundamenta a nossa gênese, colocada em atividade no decorrer da formação e do nosso desenvolvimento.

Esse meio (pré-individual), funciona tensionando nosso estado, mantendo determinado nível potencial no indivíduo que possibilite incontáveis individuações. É uma tensão que funciona como condição de vida do vivo, o que permite que o processo de individuação não cesse: enquanto a dimensão do que está individuado (modo de ser no tempo, fase: fasado) ostenta um aparente 
contorno, formando uma "homogeneidade interna", a outra dimensão anterior ao indivíduo (pré-individual) nos caracteriza como sendo essa inexistência de limites, formas e simetrias heterogêneas. (DA ESCÓSSIA; TEDESCO, 2009) Ou seja, o indivíduo enquanto indivíduo se dá através dessa ressonância interna, essa tensão: “[...] ela existe no sistema do indivíduo, e não apenas no que o indivíduo forma com o seu meio [...]" (SIMONDON, 1993, p. 105) e é o que permite não esgotar nossa realidade pré-individual, a natureza que permanece associada a nós, essa carga de estados futuros de onde podem sair outras tantas e novas individuaçóes.

Portanto, o ser para Simondon não é um universal dado, e que requer ser pensado pela potência de sua relação no processo de individuação. Não vê diferença na realidade entre homens e animais, quando reporta o vivo na mediação entre sua carga pré-individual e o que está individuado no indivíduo.

El individuo ya individuado, es decir, determinado y empobrecido en sus potenciales sólo es una abstracción, puesto que el proceso ontogenético es un complejo temporal y topológico, simultáneo y continuo. En el processo de individuación vital siempre quedará un resto pre-individual ajeno a lo individuado. (CANGI, 2008, p. 84)

O processo de desenvolvimento do vivo é sempre algo em devir, momentâneo, temporal, aquém de modelos representativos que parecem dar o indivíduo como algo constituído. Por isso é que o "resto" que carregamos, a carga tensionante indiferenciada, mantém aberto o limiar que se expressará como singularidade, na relação com o mundo.

\section{O inacabamento dos seres: do vital ao psíquico}

Extendemos essa percepção do ser de Simondon e da individuação aos modos da docência e do pensar a vida: de coisas que passam de movimentos, de sujeitos pensados como uma carga de possível, onde se consiga observar a eventualidade do ser, porque somos parte de alguma coisa que náo se definiu ainda, portando o devir; devir como uma capacidade que o ser tem de defasar-se a si próprio, "de resolver-se defasando-se”. (SIMONDON, 1993, p. 101) Resolver-se, indo de um a outro(s), cancelando-se e fazendo brotar outro(s). O devir é a própria individuação, a própria operação enquanto se efetua, fazendo com que sejamos, então, uma aparição de fases. Enquanto individuado, somos situáveis, somos "alguma coisa". Somos aí fasados, porque individualizados. Mas a operação não cessa, alguma fase de devir conduzirá a novas elaborações, a novas individuações. 
Como operamos nesse campo da individuação? Ao se perceber como um carregado de singularidades pré-individuais - constituindo-nos mesmo de diferença e nada mais que produção de diferença - vamos um pouco além, tomados por essa noção, em que, sob o olhar da processualidade, tudo que permanece em identidades fixas, de certa forma, tende a desabar.$$
* * *
$$

La diferencia esencial entre la simple vida y el psiquismo consiste en que la afectividad no juega el mismo papel en esos dos modos de existencia; en la vida, la afectividad posee un valor regulador; se eleva sobre las otras funciones y asegura esa permanente individuación que es la vida misma; en el psiquismo, la afectividad es desbordada; plantea problemas en lugar de resolverlos, y deja no resueltos los problemas de las funciones perceptivo-activas. El ingreso a la existencia psíquica se manifiesta esencialmente con la aparición de una problemática nueva, más alta, más difícil, que no puede recibir ninguna auténtica solución en el interior del ser viviente propiamente dicho, concebido en el interior de sus límites como ser individuado; la vida psíquica no es por tanto ni una solicitación ni una reorganización superior de las funciones vitales, que continúan existiendo bajo ella y con ella, sino una nueva inmersión en la realidad preindividual, seguida de una individuación más primitiva. (SIMONDON, 2009, p. 242)
\end{abstract}

Como nos situamos no mundo? Até onde vamos com nosso potencial de individuação quando falamos em viver com os outros? Destacamos a citação de Simondon para ajudar a mostrar que o psiquismo (processos mentais que nos definem como indivíduo), surge quando o estado interno próprio do vivente - o indivíduo individuado, fasado - não dá conta de seu próprio inacabamento frente ao meio e a si mesmo. Ou seja, o psiquismo permanece em seu estado rico em potenciais, até o momento em que o vivente se problematiza e o recurso psíquico emerge de sua pré-individualidade e entra em individuação. Temos, então, também o psiquismo tomado como algo em permanente diferenciação e integração de mundos.

Entende-se, a partir da citação, que o vital (orgânico) não parece ser determinante para a própria individuação do ser. Não basta sermos meio de individuação quando somos parte daquilo que acessamos com o mundo, posto que uma carga de realidade pré-individual, e de individuação psíquica, somente é acessada quando a individuação vital não dá conta. No entanto, mesmo o acesso à individuação psíquica obriga ao ser individuado a exceder-se: quando apelamos à realidade pré-individual, desembocamos em funções e estruturas que não se acabam no interior dos limites do ser vivente individuado. Daí, então, que não 
nos bastando mais na categoria de indivíduo, o psíquico passa a ser da ordem do transindividual.

Psiquismo, assim se pode dizer, é o que nos liga aos outros seres psíquicos. Produzir uma nova individuação é entrar em contato com uma ordem de realidade da qual participam outros indivíduos. Quando Simondon afirma que "[...] la vida psiquica va de lo preindividual a lo colectivo [...]" (2009, p. 244) implica uma individuação que somente se efetua quando transpomos o caráter problemático do psíquico intraindividual, conduzindo-nos ao transindividual: perpassa o indivíduo isolado porque nos arrasta a um campo que é do coletivo, do universal e comum a todos. Essa individuação vivida no coletivo para ele é, assim, permitir que indivíduo individuado se coloque em movimento, que as formas instituídas na nossa maneira de estar no mundo em um dado momento ponham-se em processo de mudança.

[...] o pré-individual, inamovível no interior do sujeito isolado, pode adquirir um aspecto singularizado nas açôes e nas emoçôes dos múltiplos: como um violoncelista que, interatuando dentro de um quarteto com o restante dos intérpretes, encontra algo de sua partitura que justo aí lhe havia escapado. (VIRNO, 2002, p. 88)

Sendo incompatível consigo mesmo e, por isso, o encontro com os outros não é algo à parte, fora de nós, mas em constante hibridação e coexistência. Nesse sentido, a afetividade e emotividade são domínios que possibilitam colocar o ser em relação com o mundo, em que as modificações afetivo-emotivas implicam a modificação do indivíduo. A afetividade assegura a pré-individualidade a individualizar-se, de aparecer, de se efetuar no coletivo. Ela é transformacional e se constitui na própria mediação entre o pré-individual e o individual: prazer e dor, tristeza e alegria são distâncias extremas em torno desta relação no ser sujeito. Interessa mais percebermos os intercâmbios afetivos e não os estados pelos quais passamos. Esse intercâmbio é efetuado através da afeto-emotividade, na ascensão do indeterminado ao presente, e que se incorpora na esfera pública. Ao viver, fluímos de um domínio de ações a outro, num contínuo emocionar (vivenciar as emoçóes) que se entrelaçam com nossas redes de conversações, ou seja, nas interações e operações corporais, mentais e simbólicas.

Podemos nos transformar nesse intercâmbio, jogando-nos a um estado de mudança, exigindo com que modifiquemos nossa ação em função de novas relaçóes a serem estabelecidas, novas formas de percepção enquanto sujeitos. Isso se efetua pela presença dos outros, no encontro com os outros, com as coisas, com o mundo. A afeto-emotividade permite que a individuaçáo passe pelo coletivo para que, entáo, deixemos de ser o que somos aqui e agora, e outros tantos possam 
surgir. Não ultrapassamos os limites da angústia, por exemplo, sentimento tão inerente aos modos de vida atuais, "[...] operação sem ação, emoção permanente que náo chega a resolver a afetividade, experimentaçáo pela qual o ser individuado explora suas dimensóes de ser, sem as poder ultrapassar [...]." (SIMONDON, 1993, p. 109), sem a esfera pública, pois somente o transindividual resolve essa problemática.

\section{0 afetivo na individuação}

O que nos interessa é a expressão da afetividade no coletivo - através da emoção - tendo ela um papel regulador na individuação. Esse afetar é afirmação do que pode um corpo, e não do que ele é, de uma natureza inerente que não se distingue de suas forças de ação e padecimento. Só podemos lidar com nossa carga pré-individual, colocá-la em processo, pôr a afetividade para funcionar em nós e ter acesso aos outros, através da emoção e, por sua vez, através dos domínios de açôes no coletivo. O coletivo, aí, deixa de ser polarizado com relação ao indivíduo, posto que o existir só toma sentido no sentir, e esse sentir só se resolve, efetua e se agencia no coletivo. Só a afetividade nos incorpora nele, e essa afetividade é do âmbito do transindividual, é o que possibilita a individuação no âmbito da coletividade. No entanto, sem a ação, a afeto-emotividade, para Simondon, não pode ser expressa. Isso implica uma presença do sujeito para os outros sujeitos, em seu aspecto relacional. A participação entre os indivíduos é possível quando as expressóes afetivo-emotivas são as mesmas:

Los vehículos de esta comunidad afectiva son entonces los elementos no solamente simbólicos sino también eficaces de la vida de los grupos; régimen de las sanciones y de las recompensas, símbolos, artes, objetos colectivamente valorizados y desvalorizado. (SIMONDON, 2009, p. 368)

Virno (2002) torna mais claro quando cita a comunicação linguística como sendo um componente do pré-individual, ou seja, dessa carga "pública" que carregamos e que é da base da afetividade. $\mathrm{O}$ uso da palavra é público, compartilhado, impessoal mas que somente na vivência grupal, é que esse impessoal se torna singular: "[...] a vida de grupo é momento de uma ulterior e mais complexa individuação $[\ldots]$. O coletivo não atenua a individuação, mas a persegue, aumentando desmesuradamente sua potência [...]”. (VIRNO, 2002 p. 87)

Linguagem que acontece nas redes de conversaçóes. Maturana e Verden-Zoller (2004) afirmam que a espécie humana apareceu quando o viver se deu no conversar e que se manteve, geração após geração, como modo de convivência. 
Todo linguajar, expressão que define essa rede de convivência na linguagem, apoia-se num suporte emocional que pode mudar com o seu curso, assim como o fluir da mudança emocional modifica a comunicação em função das mudanças que ocorrem nas formas de agir. Ou seja, os afazeres humanos ocorrem no conversar, na existência através da linguagem; conversar que é entrelaçado pelo emocionar e que, por sua vez, define as açóes que nela se coordenam. Nossa individuação se efetua através dessa rede de afetos, a qual o conversar está ligado e que se dá na convivência e aceitação mútua da vida em grupo.

Esse viver na rede de afetos sustenta a constante produção de diferença. E diferir é o que nos faz existir. Partindo disso, destensionamos a constante afirmação de uma identidade, da qual sempre se parte ou mesmo retorna, apresentando-se apenas como uma parte mínima dos seres. Se partimos da individuação como produção e afirmação de diferença (mesmo que a individuação não assegure a diferenciação, ainda que a provoque) e, esse impulso à diferença não descansa, notamos todo entrecruzamento de fenômenos. Por mais organizado que um ente seja, ele está subordinado a essa desorganização, essa tensão, servindo para mostrar o que há de mais estranho e variado, numa ânsia por uma novidade incessante.

Conduzidos por essa potência, tornamo-nos irresolutos. Um lado de nossas faces é apenas um dos diversos tantos lados com os quais nossa faceta ainda não se viu, mas que permanece associada ao que existe e que nos traduz, agora. Há aí uma fonte de possibilidades em tudo que vive e age, é a realidade não desconectada dos múltiplos em nós e de seus inerentes devires. Pode aí haver contágios de vidas, aliança entre seres, conexóes que desoperam as formas, apenas pelo que lhe coloca em processo: o seu modo de afetar, de devir. Maneira de ser, de vibrar, de sentir, em que cabem a multiplicidade e a mudança. Isso é possível porque conservamos uma dimensão pré-individual como potencial em coexistir com o transindividual.

\section{Mia Couto e as (nossas) individuações}

Já instalado na viatura, com Mariamar sentada a meu lado, despeço-me de forma desajeitada.

- Adeus, Hanifa.

- O senhor contou os leóes?

- Desde o primeiro dia que sei quantos são.

- Sabe quantos são. Mas não sabe quem são.

- Tem razão. Essa arte nunca aprenderei.

- O senhor sabe muito bem: os leóes eram três. Falta ainda um.

Olho em redor como se vigiasse a paisagem. É a última vez que contemplarei Kulumani. Será a última vez que escutarei aquela 
mulher. Com o respeito das coisas derradeiras, Hanifa Assulua sussurra:

- Eu sou a leoa que resta. É esse o segredo que só você conhece, Arcanjo Baleiro.

- Por que me conta isto, Dona Hanifa?

- Esta é a minha confissão. Esta é a corda do tempo que deixo em suas mãos. (COUTO, 2012, p. 250-251)

Leoas. Mulheres. Negros. Caçadores. Nômades. Africanos. Transitar(es) de vidas. Mia Couto escreve para familiarizar-se com a não-realidade, com os seres que não são, com pessoas que podem ser leóes, rios que são pessoas, memórias de antepassados que não conhece. Recria o real e transfigura os personagens: mostra o que aprende enquanto moçambicano, escritor e biólogo, não somente ao transcrever o que há de verossímil, mas também ao inventar personagens, inventando-se. Subverte categorias e conceitos, conhece fronteiras de culturas, línguas e etnias que lhe obrigam a revisitar palavras ao conviver com a diversidade:

[...] vou sabendo de pais que são tios, de tias que são mães, de primos que são irmãos. Tudo isto porque as relaçóes de parentesco náo podem ser traduzidas com facilidade de um assunto técnico. E vou sabendo de leóes que, afinal, são pessoas, de crocodilos que são animais de alguém, de pessoas que, depois da morte, renascem em perdizes, em leopardos [...]. (COUTO, 2011, p. 97-98)

O intento não é utilizar do literal ou do metafórico para pensar o homem, mas ele mesmo entender-se como transmutação de valores e como potência de metamorfose. Fala-se de um devir que escapa à experiência humana, suas limitações e também seus potenciais; aprendermos sobre "[...] a afección, el afecto, los modos de habitar del cuerpo y del espíritu en el espacio y en el tiempo [...]." (CANGI, 2008, p. 108-109) Abre as vigas pra mostrar que podemos ser uma constituição de vozes que lhe permitem ser singulares: dá notoriedade ao que todos somos e podemos ser, aos infinitos devires desconhecidos, ainda não individualizados, porque em processo. Mia Couto, que através da escrita, ao trazer a oralidade que é presença e existência dos povos da África, permite que se sinta esses outros em nós e coexistência com o mundo.

A família, a escola, os outros, todos elegem em nós uma centelha promissora, um território em que poderemos brilhar. Uns nasceram para cantar, outros para dançar, outros nasceram simplesmente para serem outros. Eu nasci para estar calado. Minha única vocação é o silêncio. Foi meu pai que me explicou: tenho inclinação para não falar, um talento para apurar silên- 
cios. Escrevo bem, silêncios, no plural. Sim, porque não há um único silêncio. E todo o silêncio é música em estado de gravidez. (COUTO, 2009, p. 13)

Constituímo-nos por modos de sentir: um canto, uma dança, palavra presa, ou outros ainda não (des)cobertos. Existir na produção incessante de diferença e da tensão potencial de estares. Tiremos a redoma a qual protegemos a crença num "ser". Não há início e nem fim de um movimento do indivíduo. Somos a realização de algo que se constrói em trocas com os outros e com a realidade que nos envolve, nas relaçóes que nos constituem e que constituímos no entrevaguear dos campos de efetuação da vida. Forças lançadas e efetivadas a partir da composição, cooperação e engendramento com outras forças e que nos colocam em comunicação, nos reinventam, nos modificam. Entra nisso tudo o sentir, o que nos liga uns aos outros.

Se somos definidos pelo se emocionar, por nos deixar afetar, esse mesmo emocionar define igualmente nosso modo de agir, estruturando a sociedade, e vice-versa. É o domínio da emoção que define as nossas açóes, nas relaçóes que estabelecemos com o mundo. A intenção dessa escrita, da construção do processo de individuação é, de alguma forma, repensarmos nossos feitos e conceitos quando pensamos o sujeito ao indivíduo individuado: o professor-sujeito ao indivíduo individuado, o aluno individuado. Quando pensamos em individuar o professor, náo se trata mais de perguntar o que ele é ou deve ser, mas onde ele está nesse momento. E se pensarmo-nos como individuação e não como essência, isso nos permite ser muitas coisas em determinado momento. É preciso aí aprendermos a compor os afetos, os aspectos pré-individuais de nossa experiência com os aspectos individuados. É na pluralidade de vozes, e enquanto seres que contêm o pré-individual, é que podemos mudar nossa relação com o mundo. O que fazemos com esse sentir que é inventivo é o que acaba nos definindo provisoriamente. Mas que seja sempre um provisório de nós mesmos. Que não sejamos, portanto, definitivos.

Essa diferença de percepção implica em acreditar que não podemos fazer um discurso de formação genérico de professores, onde cada um toma formas de ser no tempo, na sua relação espaço-temporal. Se não há essência em ser pensada, não podemos falar em políticas de formação para um valorizar um modo de ser que se deve exigir da profissão, mas sim modos de ser plurais, multifacetados, processuais e provisórios. Modos que quando aceitos por si próprios, ao ser percebido no encontro com os outros, ressignificam os tempos e espaços escolares e os sujeitos que os constituem. O sentir, vivido somente na coletividade, no encontro com os outros, sem esse modo emprestado de ser professor, abre um campo de possibilidades de relaçóes diversas, as quais temos visto nos espaços formativos, escolares e não-escolares. 
Em tempos e espaços "formativos", desejamos o experimentar de um tempo irreconhecido. Um tempo não-padronizado, espacializado, que parte das vezes ignora e negligencia o sentir. Que haja a liberdade de sentir qualquer coisa, modos de delírio, desvios, intermitências, gagueiras, cambaleamentos, ausências, lentidôes, silêncios, angústias. Poder inventar esses tempos e sentir as incongruências que, em última análise, não são autorizadas no tempo da identidade, do demasiado humano e idealizado.

É ignorar um tempo cronológico, informativo, subvertê-lo, permitindo que o espaço crie funcionamentos, suscetíveis ao erro. Descobre-se outros, em nossas tentaçóes de nadar, ladrar, mugir, correr, deslizar, soar, ser-se vento, rio, mulher, e qualquer coisa aquém e além disso. É subtrair hierarquias e organizações humanas, ao poder e domínio das mesmas. Livrar-se do esforço inútil de ser alguma coisa, de sustentar uma "natureza humana" que deprecie nosso fazer no mundo.

Podemos falar de uma continuidade e descontinuidade de fluxos, revelando as múltiplas singularidades. Silêncios, gestos mínimos e invisíveis atos que tem como movimento a fuga de papeis e de funçôes predefinidas. Desconstituição de sujeitos tomados como entidades acabadas, para aparecer a emergência do que é múltiplo, conjunto e compartilhado. Que os espaços da vida possam ser preenchidos mesmo de vazio e silêncio. Estamos impregnados de outros. Mas há tão pouco desses outros, e acessos dos outros em nós, nos lugares que chamamos de formativos. Tanta ausência e negação daquilo que é inerente ao estar vivo, que é mudar, durar, encarregar-se dos desejos que nos atropelam e nos fazem caminhar. Não resultar a nós mesmos em um fim: esse é o movimento que nos interessa compreender. O gosto amargo e doce na boca ao pensar-se como modos de estar, não como essência. Isso é a vida em ato, é processo de individuação. É poder, quem sabe, ser leão em metamorfose, cobra que se despe da velha pele, silêncio como vocação e música em estado de gravidez.

\section{Reflexões finais}

A inconclusão dos seres e os processos de individuação estão cada mais ausentes em uma sociedade que considera o professor cada vez mais envolto em "modos de ser" professorais, como seres acabado e definíveis. Por isso, a formação do professor pensada a partir da perspectiva da individuação legitima no homem (no vivo) o seu constante processo de subjetivação. Essa prática, por sua vez, é condição fundamental na relação homem-mundo no exercício do ser e exercer, inclusive dentro do âmbito educacional. 
Pensar na fuga do pré-determinismo, e numa formação docente menos genérica, implica em uma maior sensibilidade na desconstrução de processos já enraizados, tanto nos seres, como nos aspectos formativos. Sensibilidade que exige uma atenção especial em percebermos como agentes no processo de individuação, em que nos desenvolvemos, mudamos, manifestamos e existimos $\mathrm{O}$ devir, portanto, é uma individuação, enquanto operação que se efetua, e explica o náo-ser, tratado nesse artigo. Ser qualquer coisa, "rio, vento ou mulher", então, é poder se conceber como sistema tensionado, supersaturado, acima do nível da unidade e não como substância, matéria ou forma (identidade), posto que não nos bastamos a nós mesmos.

\section{Referências}

CANGI, A. A. Gilbert Simondon, una filosofía de la individuación (posfecho). In: SIMONDON, G. Dos leciones sobre el animal y el hombre. 1. ed. Buenos Aires: Ediciones La Cebra, 2008. 112 p.

COUTO, M. Antes de nascer o mundo. São Paulo: Companhia das Letras, 2009. 2011. . E se Obama fosse africano? e outras intervençóes. São Paulo: Companhia das Letras, . A confissáo da leoa. 1. ed. São Paulo: Companhia das Letras, 2012.

DA COSTA, R. Gilbert Simondon e a operação de individuação. In: LEÃO, L. (Org.). Interlab: labirinto do pensamento contemporâneo. São Paulo: Iluminuras, 2002. 362p.

MATURANA, H.; VERDEN-ZOLLER, G. Amar e brincar: fundamentos esquecidos do humano do patriarcado à democracia. São Paulo: Palas Athena, 2004.

ORLANDI, L. B. O indivíduo e sua implexa pré-individualidade. O reencantamento do concreto. Cadernos de subjetividade. Núcleo de Estudos e Pesquisas da Subjetividade do Programa de Pós-Graduados em Psicologia Clínica, PUC-SP, v. 1, no 1, São Paulo, 1993.

SIMONDON, G. A gênese do indivíduo. O reencantamento do concreto. Cadernos de subjetividade. Núcleo de Estudos e Pesquisas da Subjetividade do Programa de Pós-Graduados em Psicologia Clínica, PUC-SP, v. 1, no 1, São Paulo, 1993.

SIMONDON, G. La individuación a la luz de las nociones de forma y de información. 1. ed. Buenos Aires: Ediciones La cebra y Editorial Cactus, 2009. 504p.

VIRNO, P. Multidão e princípio de individuação. Revista Reichiana, ano XI, n. 11, p.7688, 2002.

Recebido em 10 de junho de 2014.

Aprovado em 25 de junho de 2015.

DOI: http://dx.doi.org/10.1590/ES0101-73302015118877 
